\title{
Importance of Undergraduate Research: Efficacy and Student Perceptions
}

\section{Prof. Sudhir Kaul, Western Carolina University}

Dr. Kaul is an Assistant Professor of Mechanical Engineering at Western Carolina University. His research interests include Fracture Diagnostics, Structural Dynamics and Control, and Motorcycle Dynamics.

\section{Dr. Chip W. Ferguson, Western Carolina University}

Chip Ferguson is the Associate Dean of the Kimmel School and Associate Professor of Engineering and Technology at Western Carolina University.

\section{Dr. Paul M. Yanik, Western Carolina University}

Dr. Paul Yanik is an Assistant Professor of Electrical and Computer Engineering Technology at Western Carolina University. His areas of research include human-robot interactions, assistive devices, pattern recognition, machine learning, and engineering education.

\section{Dr. Yanjun Yan, Western Carolina University}

Yanjun Yan received her B.S. and M.S. degrees in Electrical Engineering from Harbin Institute of Technology (China), and the M.S. degree in Applied Statistics and the Ph.D. degree in Electrical Engineering from Syracuse University. She is an assistant professor in engineering and technology at Western Carolina University. Her research interests are statistical signal processing, diagnostics, and particle swarm optimization. 


\title{
IMPORTANCE OF UNDERGRADUATE RESEARCH: EFFICACY AND STUdent PERCEPTiOnS
}

\begin{abstract}
Undergraduate research has emerged as a high-impact approach that can be used to enhance student engagement and to enrich student learning experiences. ${ }^{1}$ It is observed in the literature that undergraduate research can have an impact on student retention, and possibly attract women and ethnic minorities to science-related disciplines while playing an important role in the determination of career paths for participating students. ${ }^{2,3,4}$ While there are multiple studies on the impact of undergraduate research in social sciences and sciences, there is limited literature in the engineering disciplines. This limited literature may be attributed to multiple reasons such as a significant emphasis on mathematics and science in the first two years of engineering curriculum, a strictly sequential degree path, and a lack of flexibility in the program requirements. Engineering students often report difficulty in relating the theoretical content of the first few semesters to actual engineering applications. This study investigates the effectiveness of undergraduate research as a possible means of overcoming these student perceptions. Students are introduced to well-defined research projects at an early stage of their undergraduate degree program by adopting a scaffolding approach. The primary focus of this study is to understand student perceptions about undergraduate research in the engineering and engineering technology disciplines, with the aim of enhancing student experiences through strong mentorship and a careful choice of research projects. A survey has been developed to understand student perceptions as well as the perceptions of a few faculty mentors. The survey results are analyzed to understand whether any changes need to be made to the framework that has been adopted to introduce students to undergraduate research. Survey results from twenty six students involved in undergraduate research as part of the requirements for a scholarship program are evaluated. Subjective evaluations from a few faculty members involved in mentoring some of these undergraduate researchers are also discussed. Although both students and faculty mentors acknowledge the impact of undergraduate research experiences, some students are ambivalent about the relevance of research to academic performance. It is also observed that excessive project complexity may result in reducing student motivation unless students receive adequate support in the form of strong mentorship and appropriate guidance.
\end{abstract}

Keywords: Undergraduate research, Student perceptions.

\section{Introduction}

Undergraduate research is gaining widespread recognition as a possible means of enhancing student engagement in their program of study from a very early stage in their undergraduate program. ${ }^{1}$ Student engagement is a particular concern in engineering and engineering technology programs since it is often reported that students cannot relate to their program of study as they are required to study mathematics and physics for at least the first year of their program. ${ }^{5}$ As a result, students cannot associate their perception of engineering to the classes that they are required to take. Relatively low retention rates in the engineering programs have resulted in 
administrators and faculty seeking means of engaging students from an early stage, and attracting new students to engineering programs. Since there have been many indicators about the positive influence of undergraduate research and other co-curricular activities in the pedagogical literature, ${ }^{6}$ there is a need to directly comprehend the impact of research, as perceived by the students.

Some studies in the literature have assessed the benefits of undergraduate research as perceived by students themselves. These perceived benefits include accumulation of new skills, understanding of new content, gaining knowledge in research methodology, ability to work independently, etc. ${ }^{1,7}$ It is important to note that the perceived benefits are not limited to those students who pursue graduate degrees. ${ }^{1}$ One study discusses long term benefits reported by students involved in undergraduate research, these students also recognized the influence of a faculty mentor. ${ }^{8,9}$ Some studies even report that undergraduate research may be useful for improving the retention rates of minority students, it may be noted that this study was limited to biology students. ${ }^{10}$ The influence of undergraduate research has been studied among Science, Technology, Engineering, and Mathematics (STEM) students, with the results indicating that participation in undergraduate research can affect student decisions about enrollment in graduate and professional degrees. ${ }^{11}$ Although all of these perceived benefits are important, it is critical that involvement in undergraduate research allows the students to engage in the discipline and understand the career paths in their field of study. This is particularly important since many students participating in undergraduate research may not choose research as a career in the future. Therefore, it may be argued that undergraduate research can serve a larger purpose than the mere acquisition of skills.

This paper evaluates the effectiveness of undergraduate research by comprehending perceptions of students who have been involved with undergraduate research for more than three semesters. Self-reporting from students involved with undergraduate research is used to investigate specific aspects associated with development of skills and perceptions of challenge. Possible means of providing undergraduate research experiences to engineering and engineering technology students are also discussed in order to enhance student engagement. Perceptions of a few faculty members involved with mentoring undergraduate researchers are also evaluated. Subsequently, limitations of this study and means of expanding the scope of this study are discussed.

\section{Undergraduate Research}

Undergraduate research experiences can significantly vary from one student to another, and from one discipline to another. These experiences can include performing experimental work, assisting graduate students in their research, conducting a simulation study, performing tasks involving data collection and analysis, etc. In this paper, all these activities are generally termed together as undergraduate research as shown in Fig. 1. Typically, the main aim of undergraduate research is to introduce students to open-ended problems that may have multiple solutions, and may require a sequential, iterative and meticulous approach to analyze a problem or to arrive at the solution. Such projects often require students to go through multiple steps involving literature study, establishment of a research hypothesis, laying out a plan to answer the research questions, performing experimentation or simulations, and answering the research questions.

Undergraduate researchers may get involved with all the steps or a few steps in the research 
process, depending on the scope of their project and depending on the level of involvement of their research mentor. Involving undergraduate students in all the facets of a research project can be challenging, particularly for the students in their freshmen or sophomore years. However, it can be argued that undergraduate students can benefit from research experiences even if they are not involved with all the facets of the research project. It can be argued that involvement with undergraduate research contributes toward the development of skills that can be used in engineering problem-solving.

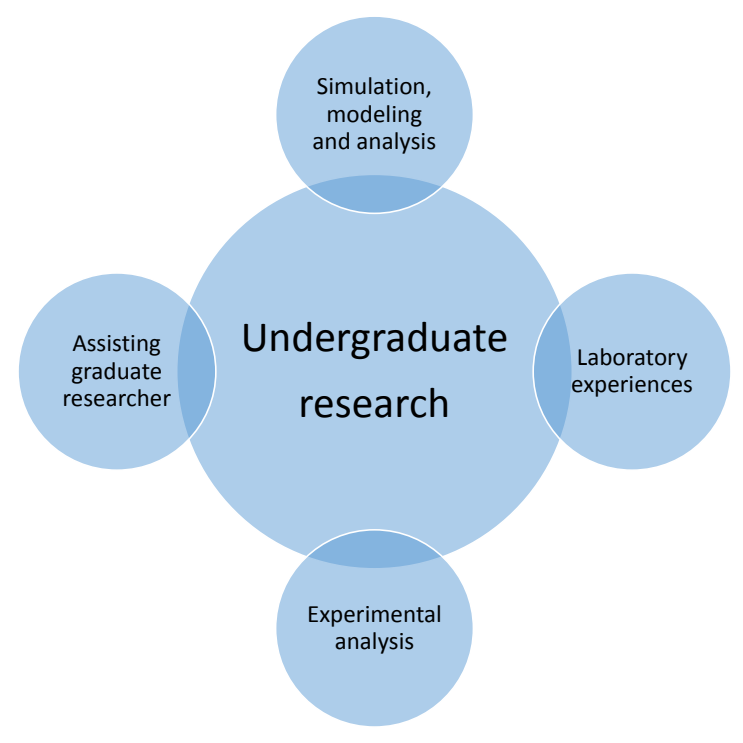

Fig. 1. Undergraduate research experiences - possible means.

Although it is very common for a mentor to identify the hypothesis or research questions for an undergraduate researcher, there are instances when undergraduate students identify their own research questions after performing a literature study. This typically depends on the nature of the student's engagement with the project and the amount of time that the student can allocate to research.

Existing literature indicates that students involved with undergraduate research demonstrate a measurable improvement in multiple aspects that are directly or indirectly associated with metacognitive development. Some of these aspects include understanding of the research process, ability to analyze data, learning to investigate supporting evidence, improvement of communication skills, enhancement of confidence, development of an understanding to connect theory with practice, inculcating an ability to work independently, etc. ${ }^{1,7,8}$ The existing literature also points out that undergraduate research seems to stimulate student interest in the subjectmatter, resulting in an enhancement of critical thinking skills, improvement of career awareness, and development of an active learning attitude. ${ }^{7}$

Students participating in this study have been involved with undergraduate research over the last three semesters. Before selecting their research topics, students were introduced to different topics of study (in the first semester of their involvement) by inviting multiple faculty members to present their current research and explain possible opportunities for undergraduate research in their research groups. A few graduate students were also invited to explain the challenges they 
had faced when they started with their research projects. These presentations were followed by introducing the students to resources available in the library such as research journals, electronic resources, etc. A librarian was invited to provide students with some tools that the students could use for research. These activities were conducted over a span of eight weeks with a weekly meeting time of 60 minutes. Students were also encouraged to contact other faculty members or their instructors to get introduced to other areas of research. After these eight weeks, students were given three weeks to select a topic of research and a mentor for their research, and then four more weeks to present an introduction to their chosen topic of research to the rest of the students. Such a timeline allowed students to carefully identify a topic that interested them, and select a mentor with whom they could form a working relationship. At the end of the first semester, each student had chosen a research topic and conducted some amount of background study. Over the next two semesters, students were required to conduct a literature study and some experimental/analytical work in their chosen area of research. Students are required to provide updates about their progress and report any problems that they may be facing. All participating students are expected to present their research findings at a regional or national conference before they graduate. It may be noted that some of the students participating in this study are also enrolled in the Honors College. These students have been encouraged to use their research topics for Honors credit in multiple classes, if approved by the instructor. The meticulous introduction to undergraduate research discussed above is a scaffolding approach and is expected to gradually develop confidence and provide students with multiple means of connecting their research with different subject-matter that they are studying in their program of study. The preliminary framework discussed above can be developed further after the first group of participating students completes their projects. One of the aims of data collection in this study is to determine whether the participating students are able to recognize the benefits of undergraduate research, and whether any improvements can be made to the framework in the near future.

While the benefits of undergraduate research have been widely reported due to engagement in active learning that goes well beyond the day-to-day class content, students participating in research may face difficulties since there are no existing answers to the problems that they may be studying. Planning a research study that typically spans across multiple semesters also requires a strong commitment and sustained motivation. The role of the mentor can be extremely crucial in assisting the students to maintain a strong level of motivation. Also, the mentor can play a key role in pointing out intangible benefits from a student's involvement in research. This is important to retain student commitment since students may feel that they are spending too much time with research at the expense of their class work. As a result, the survey developed for this study attempts to comprehend these student perceptions, among others, so that any negative perceptions can be analyzed and possibly mitigated by mentorship or by providing additional resources. The survey developed for this study includes questions about the following aspects: learning experiences resulting from undergraduate research, perception of difficulty or challenges associated with undergraduate research, thoughts about future plans that could be influenced by undergraduate research, and potential gains from undergraduate research as perceived by students. The survey has been developed such that there are a few questions on each of these aspects, and the relevant literature has been used to identify some of these aspects. ${ }^{1,2,7}$ The robustness of the survey instrument has been enhanced by including some questions that may seem repetitive or redundant. The next section presents the survey instrument that has been developed for data collection and then used to comprehend student perceptions 
about undergraduate research. Survey items associated with each aspect are combined to provide the overall average of each aspect, in addition to listing the results from each item in the survey instrument.

\section{Data Collection and Results}

This section discusses the results from an assessment of efficacy of undergraduate research conducted during Fall 2015. All the students participating in this data collection have been involved in an undergraduate research program since Fall 2014. The total number of students participating in this study represents approximately $5 \%$ of the students in engineering and technology programs at the university (with a total of 548 full time students in academic year 2015-16). It is acknowledged that the sample size is pretty low at this stage. However, after preliminary results from this study are available, a larger percentage of students can be involved at a later stage. It may be noted that the institution is classified as a regional comprehensive master-granting university with a Carnegie Community Engagement classification. A preliminary analysis has been performed to evaluate the data collected to assess the efficacy of undergraduate research, and is discussed in this section.

The data collection was performed in Fall 2015 among a group of students selected for a scholarship, resulting from a grant award. Of the 27 students selected for the scholarship, 5 females represent $18.5 \%$ and 22 males represent $81.5 \%$ of the students. From the self-reported demographic data, $78 \%$ of the students are white, $11 \%$ of the students are African American, $5 \%$ of the students are American Indian and 6\% of the students are Asian. It may be noted that out of the 27 students, only 26 students participated in this study. The data collection was conducted during the twelfth week of classes. The participating students have been engaged in undergraduate research for the last three semesters. Participation in the survey used for data collection was voluntary and participating students were required to sign an informed consent form that was approved by the Institutional Review Board (IRB) of the university. A request for Human Subjects Research was submitted to the IRB at the university, and an approval was obtained earlier during the semester after completing the required training. The survey was completed by the participating students through the selection of one out of five possible responses to each question. The survey was only conducted in the print format and participating students were given a five minute background about the study. Students were asked to respond to the following (fifteen) statements in the survey:

1. I understand the steps involved in the research process due to my involvement in undergraduate research.

2. Undergraduate research has helped me to understand the skills needed in engineering.

3. Analysis of data and interpretation of results are two critical steps in research.

4. Undergraduate research has helped me to overcome academic challenges.

5. Accomplishing tasks associated with undergraduate research gives me confidence.

6. Undergraduate research has made me appreciate the need for a combination of analysis and hands-on skills.

7. I appreciate the steps involved in executing a research project.

8. Undergraduate research is hard. 
9. Undergraduate research has made me think about the possibility of going to graduate school in the future.

10. Undergraduate research is fun.

11. Undergraduate research inspires me to learn about the work conducted by other researchers.

12. Undergraduate research has introduced me to a methodical approach for investigating a new topic of study.

13. Undergraduate research is very challenging.

14. I feel that undergraduate research is preparing me for more demanding research in the future.

15. Undergraduate research has allowed me to develop skills to identify research hypotheses or research questions.

The questions in the survey have been aimed at understanding the challenges faced by the students during undergraduate research, and the perceived benefits of undergraduate research. It may be noted that some questions may seem redundant or repetitive, this has been done to enhance the robustness and consistency of the survey instrument. All the survey responses are quantified using a 1-5 Likert scale, with 1 representing a very high level of agreement with the survey question and 5 representing a very high level of disagreement with the survey question. The 1-5 scale allows a quantitative analysis of the data in addition to a general subjective analysis of the responses obtained from the survey questionnaire.

The student responses are quantitatively evaluated by calculating a weighted average for each survey question. Since all the participants form a relatively homogeneous group with similar academic performance, a quantitative evaluation is expected to be adequate for this preliminary study even though the number of participants is relatively small. It may be noted that all the participating students have been mentored and provided with similar resources. The weighted average of student responses varies from a minimum of 1.27 to a maximum of 2.81. A low weighted average indicates the participants' agreement or strong agreement with the statement in the survey instrument. Student perception is the only metric that has been used in this study. Some of the responses are discussed further in this section. Fig. 2 shows that $73 \%$ of the participating students either strongly agree (Likert scale 1) or agree (Likert scale 2) that undergraduate research has helped them to understand the skills needed in engineering (Question \# 2). 


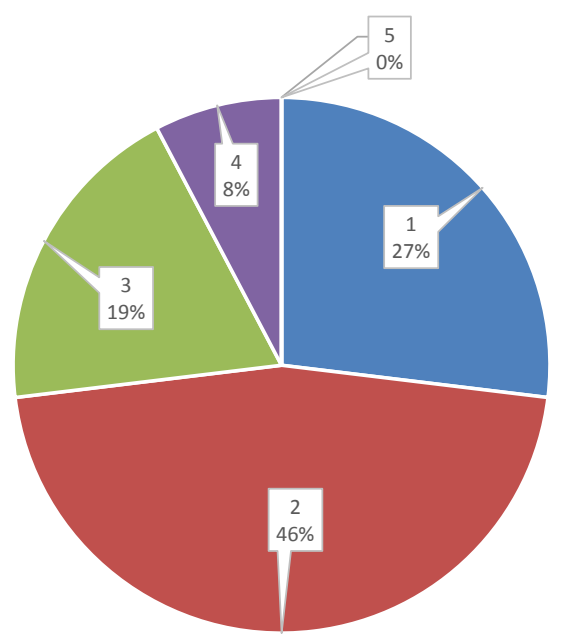

Fig. 2. Survey Response - Question \# 2 (Undergraduate research has helped me to understand the skills needed in engineering).

Fig. 3 shows that only $39 \%$ of the students either strongly agree (Likert scale 1) or agree (Likert scale 2) that undergraduate research has helped them to overcome academic challenges (Question \# 4). A significant number (38\%) expresses a neutral response (Likert scale 3) to this question and $23 \%$ disagree (Likert scale 4 ) or strongly disagree (Likert scale 5). This could be attributed to the fact that a research topic may not be directly related to the courses that the students may be taking during a specific semester. As a result, students may not see any tangible benefits from their involvement in research. It is possible that students typically associate the research topics narrowly to the courses that they may be taking at a certain stage and determine whether they are able to get some academic advantages. Such perceptions could be mitigated by making research projects available to students that directly relate to course content. However, this may not always be feasible.

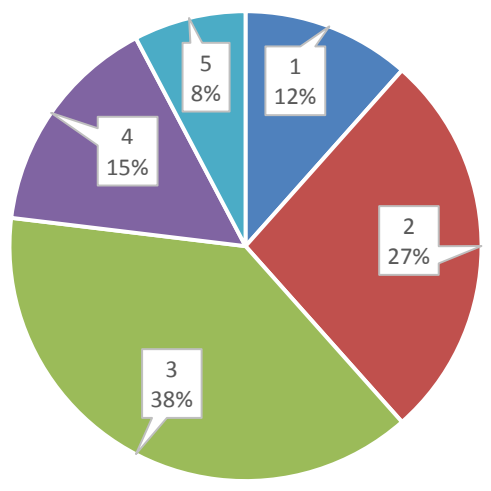

Fig. 3. Survey Response - Question \# 4 (Undergraduate research has helped me to overcome academic challenges). 
Fig. 4 demonstrates strong agreement (Likert scale 1) or agreement (Likert scale 2) with the association between accomplishment of tasks for undergraduate research and a build-up of confidence (Question \# 5), with 84\% of the students agreeing or strongly agreeing. This is an important outcome since one of the purposes of undergraduate research is to develop student confidence in their engineering ability, particularly among ethnic minorities and female students.

Fig. 4. Survey Response - Question \# 5 (Accomplishing tasks associated with undergraduate research gives me confidence).

The appreciation of a need for analysis and hands-on skills is acknowledged by $92 \%$ of the students, as can be seen from Fig. 5, with $46 \%$ strongly agreeing and $46 \%$ agreeing to Question \# 6. It seems that involvement with undergraduate research allows students to realize the importance of a balance between theory and practice.

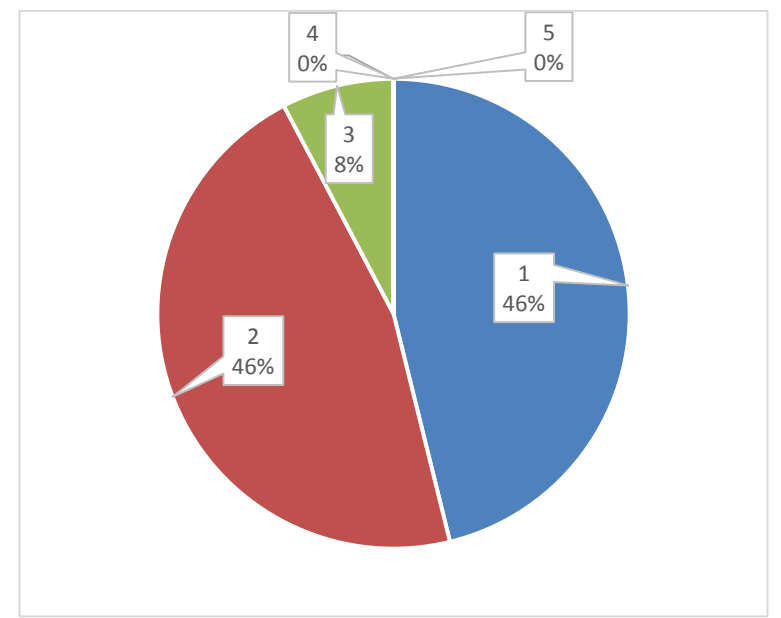

Fig. 5. Survey Response - Question \# 6 (Undergraduate research has made me appreciate the need for a combination of analysis and hands-on skills).

The response to Question \# 6 is important since students in the freshmen year tend to associate engineering with only mathematics and physics since they are required to take many of these classes as pre-requisites. Involvement with undergraduate research seems to clearly convey the 
importance of analytical and application skills to the students involved in undergraduate research.

The response to Question \# 8, shown in Fig. 6, indicates that a majority of students believe that undergraduate research is hard. As shown in Fig. 6, 84\% of respondents agree or strongly agree with the statement that undergraduate research is hard. It is important to recognize this and ensure that undergraduate researchers are provided with strong mentorship in order to make student participation in undergraduate research a positive experience. This is particularly important in the context of the response to Question \# 5 where students mention that accomplishing tasks associated with undergraduate research builds up their confidence. Therefore, it is important to prevent students from getting discouraged by providing them constant guidance and mentorship.

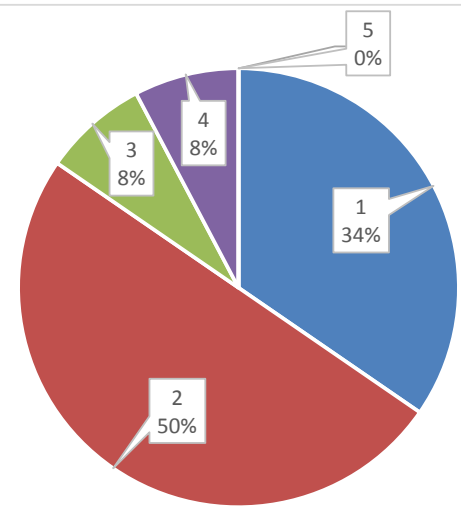

Fig. 6. Survey Response - Question \# 8 (Undergraduate research is hard).

Students believe that undergraduate research prepares them for more demanding research in the future with $73 \%$ of the participating students agreeing or strongly agreeing, as shown in the results in Fig. 7 (Question \# 14). This response is critical since it demonstrates that students are able to recognize the value of undergraduate research in the context of their future plans.

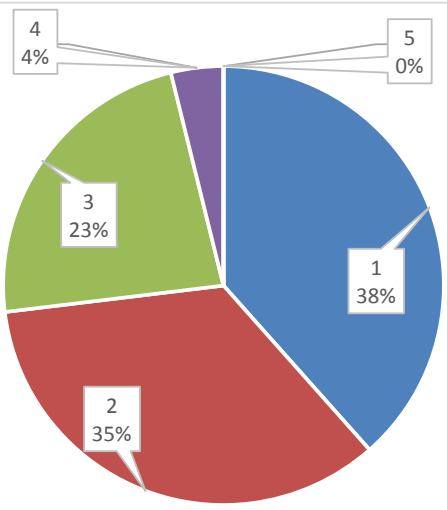

Fig. 7. Survey Response - Question \# 14 (Ifeel that undergraduate research is preparing me for more demanding research in the future). 
A summary of the results from all fifteen questions is provided in Table 1. It may be noted that the weighted average for each question is listed in the last column of this table.

Table 1. Survey Responses - Summary.

\begin{tabular}{|c|c|c|c|c|c|c|}
\hline & \multicolumn{5}{|c|}{ Survey Response (No. of students) } & \\
\hline$Q$ & 1 & 2 & 3 & 4 & 5 & $\begin{array}{l}\text { Weighted } \\
\text { Response }\end{array}$ \\
\hline 1 & 6 & 16 & 2 & 2 & 0 & 2.00 \\
\hline 2 & 7 & 12 & 5 & 2 & 0 & 2.08 \\
\hline 3 & 19 & 7 & 0 & 0 & 0 & 1.27 \\
\hline 4 & 3 & 7 & 10 & 4 & 2 & 2.81 \\
\hline 5 & 11 & 11 & 3 & 1 & 0 & 1.77 \\
\hline 6 & 12 & 12 & 2 & 0 & 0 & 1.62 \\
\hline 7 & 9 & 12 & 5 & 0 & 0 & 1.85 \\
\hline 8 & 9 & 13 & 2 & 2 & 0 & 1.88 \\
\hline 9 & 5 & 12 & 5 & 4 & 0 & 2.31 \\
\hline 10 & 4 & 15 & 6 & 1 & 0 & 2.15 \\
\hline 11 & 6 & 14 & 6 & 0 & 0 & 2.00 \\
\hline 12 & 5 & 16 & 4 & 1 & 0 & 2.04 \\
\hline 13 & 7 & 11 & 6 & 2 & 0 & 2.12 \\
\hline 14 & 10 & 9 & 6 & 1 & 0 & 1.92 \\
\hline 15 & 4 & 15 & 6 & 1 & 0 & 2.15 \\
\hline
\end{tabular}

The questions in the survey instrument can be combined into the four main aspects discussed earlier in Section 2. These aspects are evaluated by taking the combined average of the responses associated with the four aspects. The summary of these results is provided in Table 2.

Table 2. Survey Responses - Combined Averages.

\begin{tabular}{|l|l|c|}
\hline & \multicolumn{1}{|c|}{$\begin{array}{c}\text { Survey } \\
\text { Questions }\end{array}$} & $\begin{array}{c}\text { Combined } \\
\text { Weighted } \\
\text { Response }\end{array}$ \\
\hline $\begin{array}{l}\text { Understanding of research } \\
\text { process }\end{array}$ & $1,3,7,12,15$ & 1.86 \\
\hline $\begin{array}{l}\text { Understanding of engineering } \\
\text { skills }\end{array}$ & 2,6 & 1.85 \\
\hline $\begin{array}{l}\text { Perception of difficulty or } \\
\text { challenge in research }\end{array}$ & $8,10,13$ & 2.05 \\
\hline $\begin{array}{l}\text { Potential gains from } \\
\text { involvement in undergraduate } \\
\text { research }\end{array}$ & $4,5,9,11,14$ & 2.16 \\
\hline
\end{tabular}

As can be seen from the combined weighted response in Table 2, students agree that their involvement with undergraduate research has allowed them to understand the research process 
(combined weighted response of 1.86) and allowed them to gain skills that are beneficial in engineering (combined weighted response of 1.85). However, students seem to indicate that they find undergraduate research to be difficult (combined weighted response of 2.05). There is also limited agreement among students about the benefits of undergraduate research (combined weighted response of 2.16).

In order to comprehend the faculty perceptions about undergraduate research, four faculty mentors responded to the following (seven) questions in the survey:

1. Mentoring undergraduate research students is challenging.

2. Undergraduate research seems to motivate students to challenge themselves.

3. Undergraduate research students struggle with the open-ended nature of research.

4. Students involved in undergraduate research are better prepared for challenging coursework.

5. Many undergraduate research students are overwhelmed by a research project.

6. Undergraduate research is suitable for only those students who have a strong academic background.

7. Undergraduate research can be used as a means of motivating students to understand the subject-matter better.

The survey questions for the faculty mentors were selected so as to understand their perspective on some of the aspects studied through the student survey. It may be noted that all the participating faculty mentors have been serving as mentors for some undergraduate researchers for the last two to three semesters. Although it is acknowledged that the data is limited to a very small number of faculty mentors, it is important to note that many of the students who participated in the survey are being mentored by the participating faculty mentors.

All participating faculty mentors agree that mentoring undergraduate researchers is challenging, but all of them agree that undergraduate research motivates students to challenge themselves. There is also a complete agreement about the challenges posed by open-ended research projects. However, faculty mentors do not seem to have an agreement on the use of undergraduate research as a preparation for challenging coursework. There are also differing opinions about the suitability of undergraduate research for students who may not be academically strong. While some faculty mentors feel that undergraduate research is suitable for all students, others feel that undergraduate research can be beneficial to only a select few. Since the data is limited to only four faculty mentors, this will need to investigated further.

In summary, the data collected from undergraduate researchers and faculty mentors seems to indicate that the benefits of undergraduate research are clearly acknowledged. The benefits are particularly perceived to increase student confidence, allowing students to get a broader picture of the subject-matter and relate the research content to their discipline. However, students find undergraduate research to be challenging, and faculty mentors agree that students seem to struggle with the open-ended nature of projects. The scaffolding approach adopted in introducing the students to undergraduate research may need to be investigated in order to find a better fit between students and projects, and possibly mitigate student apprehensions about the challenges associated with undergraduate research. 


\section{Discussion and Conclusions}

An investigation into the effectiveness of undergraduate research has been carried out in this study by analyzing student perceptions. Although other means of enhancing student engagement such as internships, industry-sponsored projects, and student competitions have been found to be pretty successful, undergraduate research is recognized to be important for the development of critical thinking skills, and for introducing students to open-ended problems that may have multiple solutions. This is reported to be important for early career engineers, regardless of their chosen career path. ${ }^{12}$ Survey results demonstrate that students themselves recognize that undergraduate research is intellectually stimulating, and that it prepares them for future challenges while providing them with a set of skills that can be used for solving engineering problems. However, students also find research to be hard. This could be particularly relevant for freshmen and sophomore students who may struggle with relating the course content with their project. It is expected that students find involvement with undergraduate research as one possible means of developing analytical and professional skills that they can use in a rapidly changing environment where employers are seeking a very diverse set of skills from graduating students. ${ }^{13}$ Survey results indirectly indicate that the scaffolding approach used in introducing students to undergraduate research has been useful. However, further development of the framework used to introduce undergraduates to research is needed. In the long term, undergraduate research could be integrated into curriculum through a series of courses that are required to meet critical program outcomes. This can be done over multiple semesters so as to allow students to select a project of their interest and a mentor they prefer. The results of this study indicate that students find undergraduate research to be most useful when they enjoy the project, and when they have a strong relationship with their mentor.

This study has been limited to a relatively small number of participants. Future work will investigate a larger group of students and attempt to examine whether there are any direct cognitive advantages to introducing engineering students to undergraduate research. A relationship, if any, between participation in undergraduate research and overall academic performance will also be examined in the future by using a control group to compare the academic performance of students participating in undergraduate research with non-participating students. Future work will also investigate the pros and cons of the framework that has been used in this study to introduce students to undergraduate research. The consistency of the aspects investigated through the survey instrument will be evaluated in a future study.

\section{References}

1. Lopatto, D., 2007, "Undergraduate research Experiences Support Science Career Decisions and Active Learning," CBE - Life Sciences Education, 6, pp. 297-306.

2. Kardash, C. M., 2000, "Evaluation of undergraduate experience: Perception of undergraduate interns and their faculty members," Journal of Educational Psychology, 92, pp. 191-201.

3. Ansari, J., Ansari, A., Agrawal, K., 2009, "Enhancing Undergraduate Research Infrastructure," Proceedings of the ASEE Annual Conference and Exposition, Austin, TX.

4. Evans, M., Welch, R., 2004, "Undergraduate Independent Study Research Projects," Proceedings of the ASEE Annual Conference and Exposition, Salt Lake City, UT. 
5. Meyer, M., Marx, S., 2014, "Engineering Dropouts: A Qualitative Examination of Why Undergraduates Leave Engineering," Journal of Engineering Education, 103, pp. 525-548.

6. Wilson, D., Jones, D., Kim, M. J., Allendoerfer, C., Bates, R., Crawford, J., Floyd-Smith, T., Plett, M., Veilleux, N., 2014, "The Link between Cocurricular Activities and Academic Engagement in Engineering Education," Journal of Engineering Education, 103, pp. 625-651.

7. Seymour, E., Hunter, A., Laursen, S. L., Deantoni, T., 2004, "Establishing the Benefits of Research Experiences for Undergraduates in the Sciences: First Findings from a Three-Year Study," Science Education, 88, pp. 493-534. 8. Zydney, A. L., Bennett, J. S., Shahid, A., Bauer, K. W., 2002, "Impact of Undergraduate Research Experience in Engineering," Journal of Engineering Education, 91, pp. 151-157.

9. Boyd, M., Wesemann, J. (eds.), 2009, "Broadening participation in undergraduate research: fostering excellence and enhancing the impact," Washington, DC: Council on Undergraduate Research.

10. Jones, M. T., Barlow, A. E. L., Villarejo, M., 2010, "Importance of Undergraduate Research for Minority

Persistence and Achievement in Biology," The Journal of Higher Education, 81, pp. 82-115.

11. Eagan, M. K., Hurtado, S., Chang, M. J., Garcia, G. A., Herrera, F. A., Garibay, J. C., 2013, "Making a

Difference in Science Education: The Impact of Undergraduate Research Programs," American Education Research Journal, 50, pp. 683-713.

12. Brunhaver, S., Gillmartin, S. K., Grau, M. M., Sheppard, S., Chen, H. L., 2013, "Not All the Same: A Look at Early Career Engineers Employed in Different Sub-Occupations," Paper \# 6119, Proceedings of the ASEE Annual Conference \& Exposition, Atlanta, GA.

13. Froyd, J. E., Wankat, P. C., Smith, K. A., 2012, "Five Major Shifts in 100 Years of Engineering Education," Proceedings Of The IEEE, 100, pp. 1344-1360. 